\title{
Cloning, Expression Pattern Analysis and Subcellular Localization of Resveratrol Synthase Gene in Peanut (Arachis hypogaea L.)
}

\author{
Fanghe Zhu ${ }^{1 *}$, Jingluan Han ${ }^{2}$, Shumei Liu1, Xiaoping Chen'1, Rajeev K. Varshney³, \\ Xuanqiang Liang1" \\ ${ }^{1}$ Crops Research Institute, Guangdong Academy of Agricultural Sciences, Guangzhou, China \\ ${ }^{2}$ College of Life Science, South China Agricultural University, Guangzhou, China \\ ${ }^{3}$ International Crops Research Institute for the Semi-Arid Tropics (ICRISAT), Patancheru, India \\ Email: gxzhufanghe@163.com, 418897003@qq.com, liushumei1117@163.com, xpchen1011@gmail.com, \\ R.K.Varshney@CGIAR.ORG, "Liang-804@163.com
}

Received 24 September 2014; revised 23 October 2014; accepted 9 November 2014

Copyright (C) 2014 by authors and Scientific Research Publishing Inc.

This work is licensed under the Creative Commons Attribution International License (CC BY). http://creativecommons.org/licenses/by/4.0/

(c) (i) Open Access

\section{Abstract}

Resveratrol synthase (RS) is a key enzyme that plays a critical role in the resveratrol synthesis pathway. In this study, six RS genes were isolated and characterized from peanut variety "Zhenzhu Hong" by silico cloning and RT-PCR. Bioinformatics analysis showed that deduced amino acid sequences of the six cloned RS genes were highly conserved with a similarity from $95 \%$ to $99 \%$ when compared to the RS genes which had been deposited at the GenBank. The results of amino acid sequences analysis showed six RS proteins contained the Chal_Sti_Synt_N and ACP_Syn_III_C domains and can be classified to same family but with different evolutionary distance. Expression pattern analysis by QRT-PCR provided evidence indicating that the mRNA of six RS genes were primarily expressed in the peanut shell at different developmental stages with different expression levels, but only lower levels of them were evident in the peanut kernel. The subcellular localization of RS protein in onion epidermal cell was performed by Agrobacterium tumefaciens-mediated transformation and the green fluorescent was monitored by confocal fluorescence microscopy. The results indicated that, RS1 and RS5 were located in the nucleus and plasma membrane respectively, while the RS2, RS3, RS4 and RS6 were located in both nucleus inner membrane and plasma membrane. The data will provide basic information for elucidating the regulatory mechanisms and enzyme kinetics underlying the RS genes in the resveratrol synthase pathway.

\footnotetext{
${ }^{*}$ These authors contributed equally to this work.

${ }^{\#}$ Corresponding author.
}

How to cite this paper: Zhu, F.H., Han, J.L., Liu, S.M., Chen, X.P., Varshney, R.K. and Liang, X.Q. (2014) Cloning, Expression Pattern Analysis and Subcellular Localization of Resveratrol Synthase Gene in Peanut (Arachis hypogaea L.). American Journal of Plant Sciences, 5, 3619-3631. http://dx.doi.org/10.4236/ajps.2014.524378 


\section{Keywords}

\section{Peanut (Arachis hypogaea L.), Resveratrol Synthase Gene, Expression Pattern Analysis, Subcellular Localization, Development}

\section{Introduction}

Resveratrol (Trans-3,5,4'-trihydroxy stilbene) is a natural plant phytoalexin which produced by plants in response to bacterium, fungal and other biotic or UV irradiation, wounding and other abiotic stress. It is present in more than 70 dietary plant species and with high concentration reported in grapes, berries and peanuts [1] [2]. Resveratrol exhibits several biological properties which include anti-microbial [3] [4], anti-oxidant [5], antimutagen [6], anti-inflammatory [7], anti-neoplastic [8] [9], and as a cholesterol reducing agent [10]. It also contributes to inhibition, delay, reversion of cellar events associated with heart disease and tumorigenesis [11]-[15]. The concentrations of resveratrol in most of plants is at the low level under ambient environmental conditions, however the compound is accumulated under stressful conditions which include pathogenic infection, but and other biotic stresses or UV irradiation, wounding and other abiotic stresses and functions to protect the plants from attacks [16]-[20].

Resveratrol is synthesized by the catalysis of resveratrol synthase (RS) using one molecule p-coumaroyl-CoA and three molecules of malonyl-coenzyme A [1] [21]. A number of RS genes have been cloned and identified from several plant species, including peanut, pines and grape. The first two RS genes cloned from peanut cell cultures was at 1988 [22] and four RS genes were identified at 1990 [23], and a range of RS genes have been cloned from peanut [24] [25]. Genetic engineering of plants with the objective of increasing the expression of RS can be exploited in order to develop plants with a higher level of resistance to pathogens [26]-[28]. The first reported transformation of foreign phytoalexin expression in a novel plant resulted disease resistance, was performed with a peanut RS gene introduced into tobacco, resulted in the rapid accumulation of resveratrol following treatment of cell suspension cultures with fungal elicitor [29]. From then on, RS genes have been introduced into a number of plants, including rice, barley and wheat, alfalfa, kiwifruit, grapevine, apple, aspen, papaya, white poplar, oilseed rape, banana, Rehmannia, tomato, Arabidopsis, lettuce, pea, and hop [30]-[33].

Although the resveratrol biosynthesis and regulation mechanism of RS gene at transcriptional level especially under the biotic and abiotic stress in peanut has been extensively studied in recent years [21] [34], but the regulation mechanism at transcriptional and translational level and the mechanism to antimicrobial still remains obscure. Here, we cloned and characterized six RS genes from peanut variety "ZhenZhuHong" by used the silico cloning and RT-PCR methods, and the sequences characters were analyzed by bioinformatics methods. To primarily study the distribution of six RS genes, QRT-PCR was applied to determine the mRNA expression pattern of them in peanut kernel and shell at different development stages. Analysis the subcellular location of the RS protein was carried out by Agrobacterium mediated transformation of onion epidermal cells with gene constructs representing each of the RS genes followed by-monitoring using confocal fluorescence microscopy. The study provides an important molecular basis for conducing further analysis on the functions, regulatory mechanisms and enzyme kinetics underlying the RS genes in resveratrol synthase process.

\section{Materials and Methods}

\subsection{Plant Materials}

The peanut variety "ZhenZhuHong” was planted in the experimental field of Guangdong Academy of Agricultural Sciences with $18^{\circ} \mathrm{C}-31^{\circ} \mathrm{C}$, long-day photoperiod and acid soil Seven samples at different developmental stages (Figure 1) were retrieved and total RNA was extracted. These were: peanut pods of tissue differentiation stage (I-P), kernel (II-K) and shell (II-S) of cotyledon elongation stage, kernel (III-K) and shell (III-S) of main leaf elongation stage, kernel (IV-K) and shell (IV-S) of mature stage (IV-K). Samples from six individual plants were pooled and frozen immediately in liquid nitrogen and then stored at $-80^{\circ} \mathrm{C}$ prior to total RNA extraction.

\subsection{RNA Extraction and Reverse Transcription}

Total RNA was extracted from the seven collected samples using TRIzol reagent (Invitrogen, USA) following 

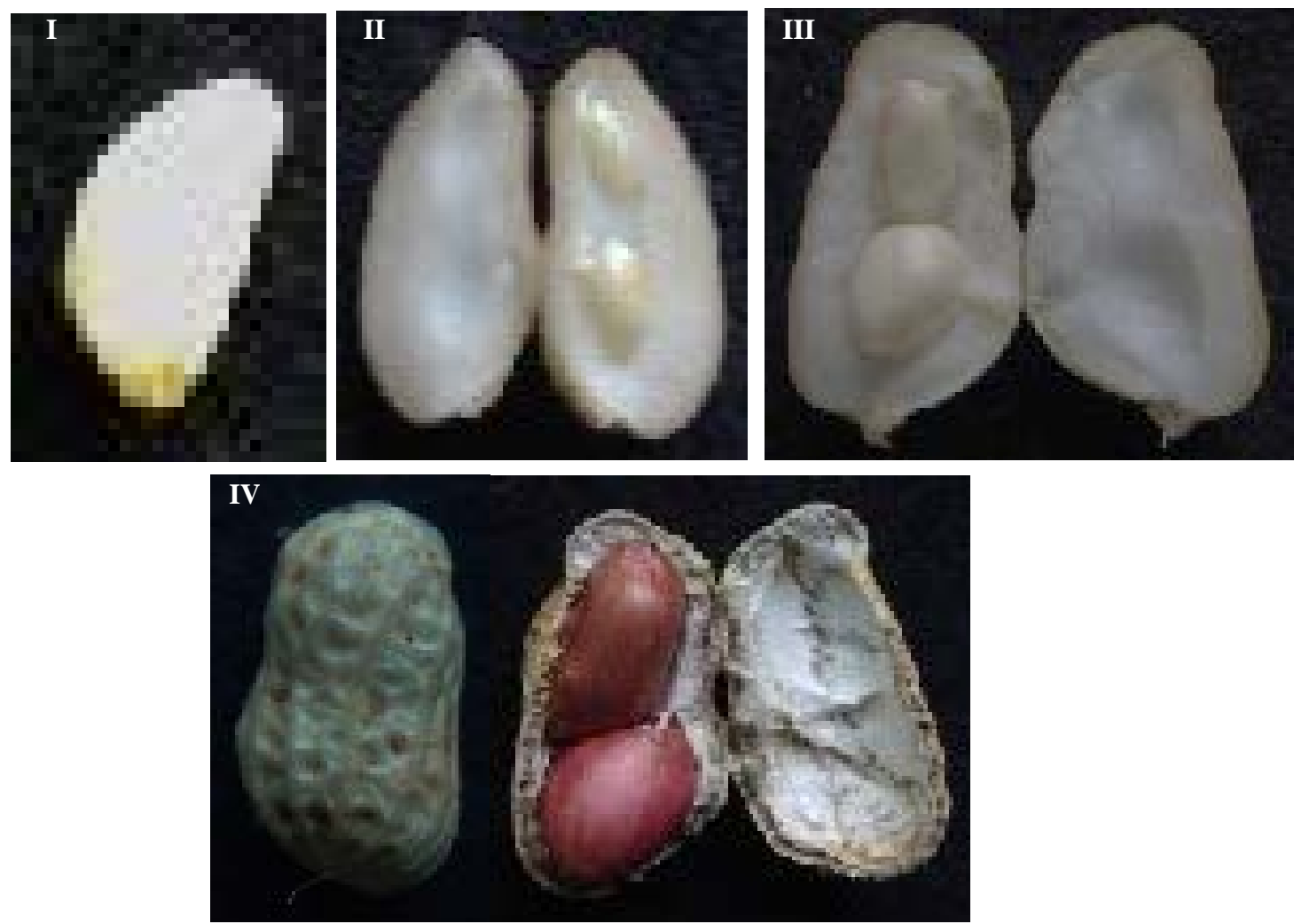

Figure 1. The pods characters of “Zhenzhu Hong” at different development stage. I: Tissue differentiation stag, II: Cotyledon elongation stage, III: Main leaf elongation stage, IV: Mature stage.

the manufacture's instruction and then treated with RNase-free DNase I (Promega, USA) to remove contaminating genomic DNA. First-strand cDNAs were synthesized from each sample by using 50 pmol of poly(T) $)_{12-18}$ primer and SuperScript ${ }^{\mathrm{TM}}$ III First-Strand Synthesis System according the standard protocol (Invitrogen, USA). For each sample, two separated reverse transcription reactions were pooled.

\section{3. cDNA Cloning}

The full length reference cDNA sequence of peanut RS genes firstly were cloned by silico cloning methods. The primary peanut EST sequence in previously study were used in a search of the available peanut EST database using the BLAST algorithm (http://www.ncbi.nlm.nih.gov/BLAST), the selected ESTs were assembled by using the DNAStar program (Madison, USA). The homology or similarity searches of the assemble sequences by using Nucleotide BLAST and protein BLAST (http://www.ncbi.nlm.nih.gov/BLAST/) against public databases (GenBank), the putative encoding RS genes were selected to further study (as showed in Table 1). Then RT-PCR amplification was performed to cloning and validated the ORF of six RS genes. The gene-specific primers (Table 1: RS-ORF) were designed by using the Primer Premier 5.0 (http://www.premierbiosoft.com). The mixture cDNA of seven samples was used to RS genes cDNA cloning, the PCR program were performed according to the standard condition and protocols by Ex-Taq PCR Kit (Takara, Japan). PCR products were subsequently fractionated on $1.0 \%$ agarose gel and the DNA fragments were purified by DNA Gel/PCR purification Miniprep kit (Biomega, USA), then subcloned into pMD18-T Vector (Takara, Japan). Clones containing target DNA inserts were screened by PCR with the M13 forward and reverse primers (M13F:5'-GTAAAACGACGTCCAGT-3', M13R: 5'-CAGGAAACGACTATGAC-3'). The DNA sequencing were performed with the M13 forward and reverse primers by the BGI corporation (China).

\subsection{Bioinformatics Analysis}

All the individual sequences by raw sequencing data were removed from the vector Sequences by the VecScreen 
Table 1. Primers used in this study.

\begin{tabular}{|c|c|c|c|}
\hline Code & Sequence (5' - 3') & Use & Accession NO. \\
\hline RS1-ORF-F & ATGGTGTCTGTGAGTGGAATTCG & \multirow{2}{*}{ ORF Cloning } & \multirow{2}{*}{ AY170347 } \\
\hline RS1-ORF-R & TTATATGGCCATGCTGCGGAG & & \\
\hline RS2-ORF-F & ATGTATTTAACAGAAGAAATACTCA & \multirow{2}{*}{ ORF Cloning } & \multirow{2}{*}{ EU384706 } \\
\hline RS2-ORF-R & TTATATGGCCACACTGCG & & \\
\hline RS3-ORF-F & ATGTACTTAACGGAAGAGATACTGA & \multirow{2}{*}{ ORF Cloning } & \multirow{2}{*}{ HM130568 } \\
\hline RS3-ORF-R & GAGTCCAGGACCAAATCCAA & & \\
\hline RS4-ORF-F & ATGGTGTCTGTGAGTGAGATCC & \multirow{2}{*}{ ORF Cloning } & \multirow{2}{*}{ JQ728483F } \\
\hline RS4-ORF-R & TCAGATGGTCACACTACGAAGA & & \\
\hline RS5-ORF-F & ATGGTGTCTGTGAGTGGAATTCG & \multirow{2}{*}{ ORF Cloning } & \multirow{2}{*}{ L00952 } \\
\hline RS5-ORF-R & TTATATGGCCACACTGCGGAG & & \\
\hline RS6-ORF-F & ATGTGCGCATACAAAGCACC & \multirow{2}{*}{ ORF Cloning } & \multirow{2}{*}{ X62300 } \\
\hline RS6-ORF-R & TCATATGGCCACGCTGCG & & \\
\hline RS1-QRT-F & ССТACСTTTGAGATCGTTTCAACC & \multirow{2}{*}{ QRT-PCR } & \\
\hline RS1-QRT-R & AGTGCGTCGTTGATGTTTTGTG & & \\
\hline RS2-QRT-F & AAGGCCCTGCAACCGTATTAG & \multirow{2}{*}{ QRT-PCR } & \\
\hline RS2-QRT-R & TCTTGAGGTCGGTCATGTGCT & & \\
\hline RS3-QRT-F & AAGTGAACTTAAAACCAGAGAAGATG & \multirow{2}{*}{ QRT-PCR } & \\
\hline RS3-QRT-R & CTTCAAGGGATTTTTTCCTCATT & & \\
\hline RS4-QRT-F & ATCCGCAACGTTCAAAGAGC & \multirow{2}{*}{ QRT-PCR } & \\
\hline RS4-QRT-R & GTTTGATGGATTTGCCGTGC & & \\
\hline RS5-QRT-F & GACAAGCATTGTTTGCCGAT & \multirow{2}{*}{ QRT-PCR } & \\
\hline RS5-QRT-R & TTGAGCGCGTCATTGATATTT & & \\
\hline RS6-QRT-F & ATTAGATATCCСTCCATATATGCG & \multirow{2}{*}{ QRT-PCR } & \\
\hline RS6-QRT-R & ATAATATATAGGCCAATTAGGACCTT & & \\
\hline Actin-F & GATTGGAATGGAAGCTGCTG & \multirow{2}{*}{ Normalization for QRT-PCR } & \\
\hline Actin-R & CGGTCAGCAATACCAGGGAA & & \\
\hline RS1-SCL-F & CGCGGATCCGCGATGGTGTCTGTGAGTGGAATTCG & \multirow{2}{*}{ Subcellular Localization } & \\
\hline RS1-SCL-R & AAAACTGCAGTATGGCCATGCTGCGGAG & & \\
\hline RS2-SCL-F & CGCGGATCCGCGATGTATTTAACAGAAGAAATACTCA & \multirow{2}{*}{ Subcellular Localization } & \\
\hline RS2-SCL-R & AAAACTGCAGTATGGCCACACTGCG & & \\
\hline RS3-SCL-F & CGCGGATCCGCGATGTACTTAACGGAAGAGATACTGA & \multirow{2}{*}{ Subcellular Localization } & \\
\hline RS3-SCL-R & AAAACTGCAGGAGTCCAGGACCAAATCCAA & & \\
\hline RS4-SCL-F & CGCGGATCCGCGATGGTGTCTGTGAGTGAGATCC & \multirow{2}{*}{ Subcellular Localization } & \\
\hline RS4-SCL-R & AAAACTGCAGGATGGTCACACTACGAAGA & & \\
\hline RS5-SCL-F & CGCGGATCCGCGATGGTGTCTGTGAGTGGAATTCG & \multirow{2}{*}{ Subcellular Localization } & \\
\hline RS5-SCL-R & AAAACTGCAGTATGGCCACACTGCGGAG & & \\
\hline RS6-SCL-F & CGCGGATCCGCGATGTGCGCATACAAAGCACC & \multirow{2}{*}{ Subcellular Localization } & \\
\hline RS6-SCL-R & AAAACTGCAGTATGGCCACGCTGCG & & \\
\hline
\end{tabular}

The sequences underlined are the corresponding restriction enzyme cutting sites. GGATCC represent BamH I cutting site, CTGCAG represent Pst I cutting site. 
in NCBI (http://blast.ncbi.nlm.nih.gov/), and then the sequence reads were assembled into contiguous sequences with the Seqman and translate into Amino-acid sequence with the Editseq from the Lasergene package (http://www.dnastar.com/). The homology or similarity searched by using nucleotide BLAST and protein BLAST (http://www.ncbi.nlm.nih.gov/BLAST/). The protein molecular weight prediction and isoelectric point were calculated by ExPASY (http://www.expasy.ch/). The motif search was performed online with SMART protein analysis program (http://smart.embl-heidelberg.de/). Multiple amino-acid sequences alignment and phylogenetic tree (by NJT and the number of bootstrap replicates is 500) of the RS genes translated polypeptide sequences were done using CLUSTALW, constructed by MEGA 4.0 program, the alignment picture was showed by GeneDoc.

\subsection{Expression Pattern Analysis}

The cDNA of seven samples as described in previously were used to expression pattern analysis by Light Cycler 480 system with the "LC Fast Start DNA Master SYBER GREEN I kit" (Roche, Germany). Gene-specific primers were designed base on the cloned RS genes sequence, peanut Actin1 gene which was expected to show a constitutive expression pattern was used as the control to normalize the expression of RS genes (Table 1: RSQRT, Actin1). The QRT-PCR reactions were run for two-step PCR as follows: $95^{\circ} \mathrm{C}$ for $10 \mathrm{~s} ; 40$ amplification cycles at $95^{\circ} \mathrm{C}$ for $5 \mathrm{~s}, 60^{\circ} \mathrm{C}$ for $10 \mathrm{~s}$ and $72^{\circ} \mathrm{C}$ for $10 \mathrm{~s}$. At the end of each reaction, the fluorescence signal was detected, and used to generate an amplification profile. All PCR amplifications were performed in triplicate for each RNA sample and gene expression levels were quantified relative to Actin1 expression using Light-Cycler Software version 1.5 (Roche) based on the manufacturer's instructions. All tests were based on the same pooled cDNA to insure uniformity of the results. Difference in gene expression between groups were evaluated using Student's-test and were considered statistically significant at $\mathrm{P}<0.05$.

\subsection{Subcellular Localization}

Gene-specific primers for RS were designed to incorporate BamHI and PstI retriction sites at the N-terminus of the forward and reverse primers (Table 1: RS-SCL). The products of PCR amplions were then cloned into the modified pCAMBIA1302 vectors (CAMBIA, Australia), to generate the pCAMBIA1302-P CAMV $355_{3}:$ RS:mGFP and then verified by restriction and sequencing analysis. Six recombinant plasmid and pCAMBIA1302 vectors were introduced into onion epidermal cells by an Agrobacterium-mediated system respectivly, incubated on 1/2 MS medium for $24 \mathrm{~h}$ at $26^{\circ} \mathrm{C}$ in darkness, and the fluorescence of GFP was visualized through a fluorescence microscope. All transient expression assays were repeated at least three times

\section{Results}

\subsection{Molecular Cloning of RS Genes from Peanut}

BLAST searches by using the EST sequences which obtained in previously, six RS genes candidates plus putative sequences were selected for further analysis (Table 1). Primers were designed based on these reference sequences and six cDNA fragments corresponding to the RS genes from peanut "Zhenzhu Hong" variety were generated by RT-PCR (Figure 2). By cloned and sequenced of six RS genes, the complete ORF capable of varying length and encoding protein of different residues length were conducted, the molecular mass and isoelectric point (pI) were also calculated as showed in Table 2.

\subsection{Bioinformatics Analysis}

Base on the deduced amino acid sequence, six cloned RS genes share with 95\% - 99\% identity by BLASTP searches, and showing 92\% - 98\% identity with those peanut RS genes in the public database. The amino acid alignment results also show the high conservation of RS gene, amino acid variation only at a few sites (Figure 3). And all of them contain two conserved domains Chal_Sti_Synt_N and ACP_Syn_III_C domain supported by SMART protein analysis program. The high similarities mean that these RS proteins share significant structural similarity in a superfamily.

To investigate the evolutionary relationship between RS genes and other peanut RS genes sequences in public database, a phylogenetic tree was constructed with neighbor-joining algorithms by using the translated polypeptide 


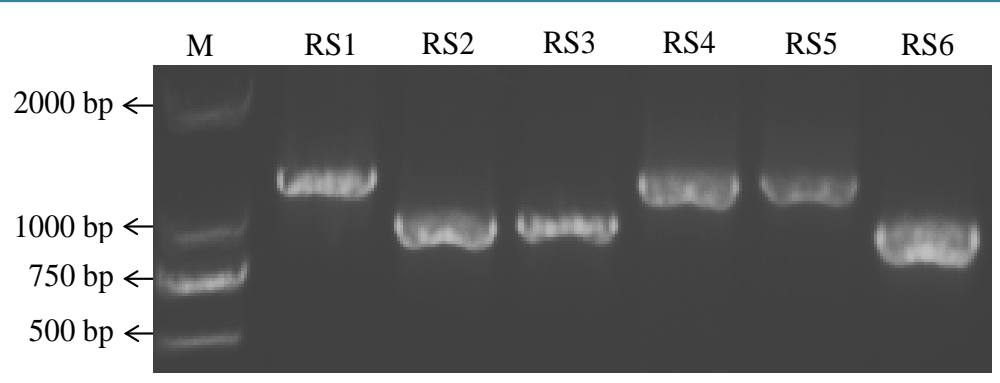

Figure 2. Amplification six RS genes from peanut "ZhenZhuHong” variety. M: Marker 2000. RS1-RS6: the PCR products of six RS genes amplified from the cDNA of peanut "Zhenzhu Hong” variety.

Table 2. Bioinformatics analysis of six RS genes.

\begin{tabular}{ccccc}
\hline RS gene & ORF in length (bp) & Encoding protein residues & Molecular mass (Da) & Isoelectric point (pI) \\
\hline RS1 & 1170 & 389 & 42784.5 & 6.62 \\
RS2 & 963 & 320 & 34856.2 & 5.08 \\
RS3 & 927 & 308 & 33611.8 & 5.17 \\
RS4 & 1170 & 389 & 42897.4 & 5.80 \\
RS5 & 1170 & 389 & 42741.2 & 5.58 \\
RS6 & 924 & 307 & 33345.5 & 5.25 \\
\hline
\end{tabular}
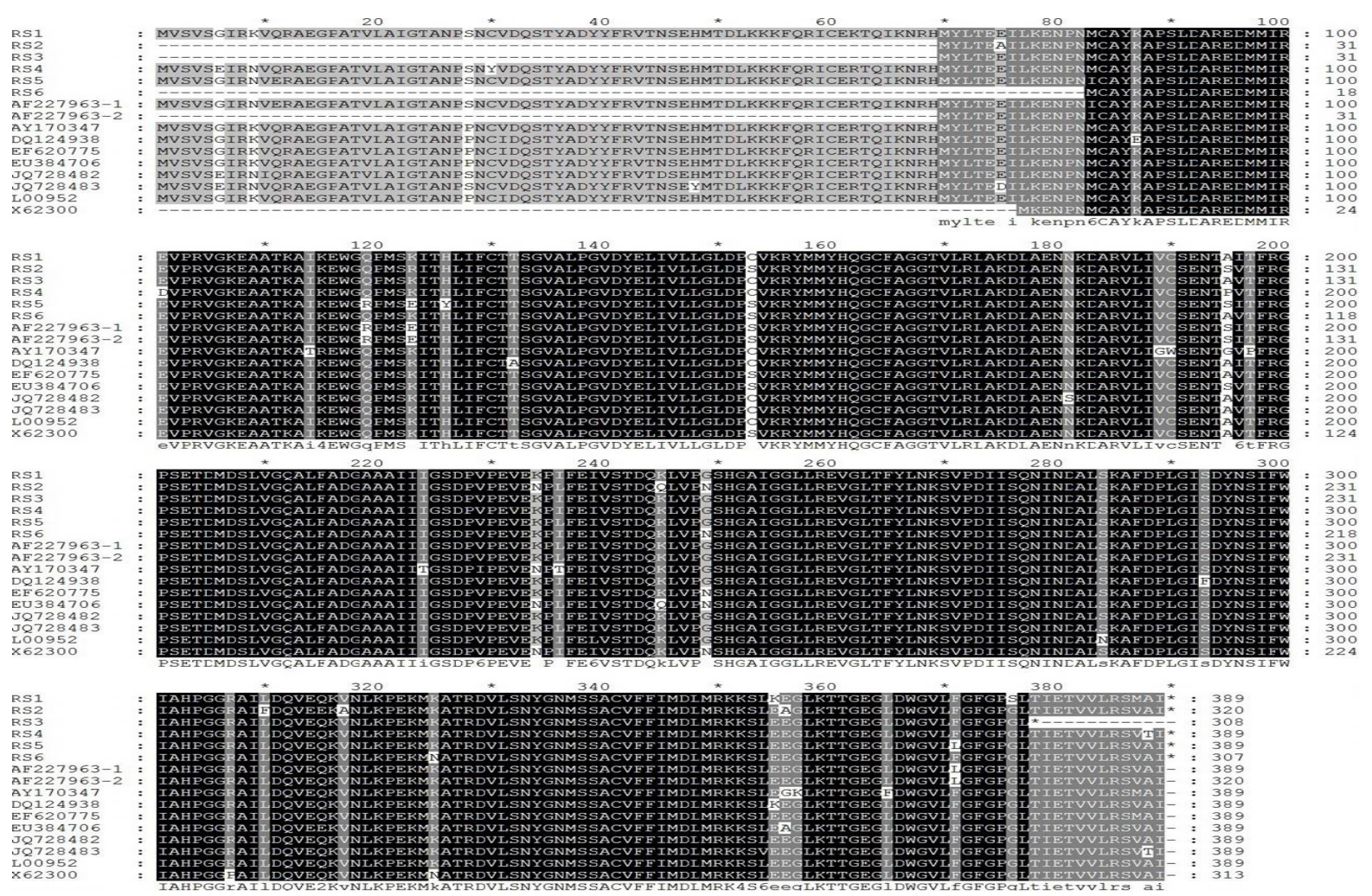

Figure 3. Amino acid alignments of RS genes in peanut. Deduced amino acid sequences for cloned RS genes from peanut "Zhenzhu Hong" variety (RS1 - RS6) and those peanut RS genes available in public database were aligned by using CLUSTALX of MEGA 4 program. Amino acid residues common to all protein are highlighted in black, the lower amino acid residues common are highlighted in light gray. 
sequence of RS genes in relation to those proteins from database (Figure 4). The phylogenetic tree analysis revealed that all of these protein group into a branches without AY170347. The evolutionary relationship also proves the high similarity and conservation of RS gene in peanut.

BLASTP searches revealed that there were some difference between the deduced amino acid sequence of cloned RS genes and the reference sequences: the identity of RS1 and AY170347 is 95\%, and RS2-EU384706 is 99\%, RS3-HM130568 IS 100\%, RS4-JQ728483 is 98\%, RS5-L00952 is $96 \%$, RS6-X62300 is $98 \%$. These sequence diversity indicated that although the RS gene exhibited interspecific variation.

\subsection{Expression Pattern Analysis}

In order to examine the differential distributions of RS genes in peanut kernel and shell tissue (separately extracted the total RNA from them) at different developmental stages in "Zhenzhu Hong” variety (the seven samples as described in material and Figure 1), the relative mRNA expression levels of six RS genes were evaluated by QRT-PCR (Figure 5). Six RS genes preferentially expressed in peanut shells in the seven sample examined, but only lower levels of them were evident in the peanut kernel. The expression levels of six RS genes in the peanut kernel were below 0.05 fold compare with the expression level of Actin1 gene. Five of the RS genes express in shells show the same pattern, the expression level of RS genes increase gradually with the developmental stage and reach at the top point of mature stage except RS4 being higher at main leaf elongation stage. Among the six RS genes expressed in shell, RS1 is the highest expression at 16 times normalized by Actin1 gene follow by were RS3 and RS6 at about 12 fold, RS2 is about 5 times and RS5 is 3 fold, while RS4 is at the lowest express level only about 1.5 fold normalized with Actin1 gene.

\subsection{Subcellular Localization in Onion Epidermal Cell}

To determine the subcellular location patterns of six RS proteins, GFP fluorescence signals were examined by confocal fluorescence microscopy in onion epidermal cells. We constructed a chimeric gene for the fusion of protein encoded by the six RS genes ORF to the N-terminus of synthetic green fluorescent protein. And chimeric

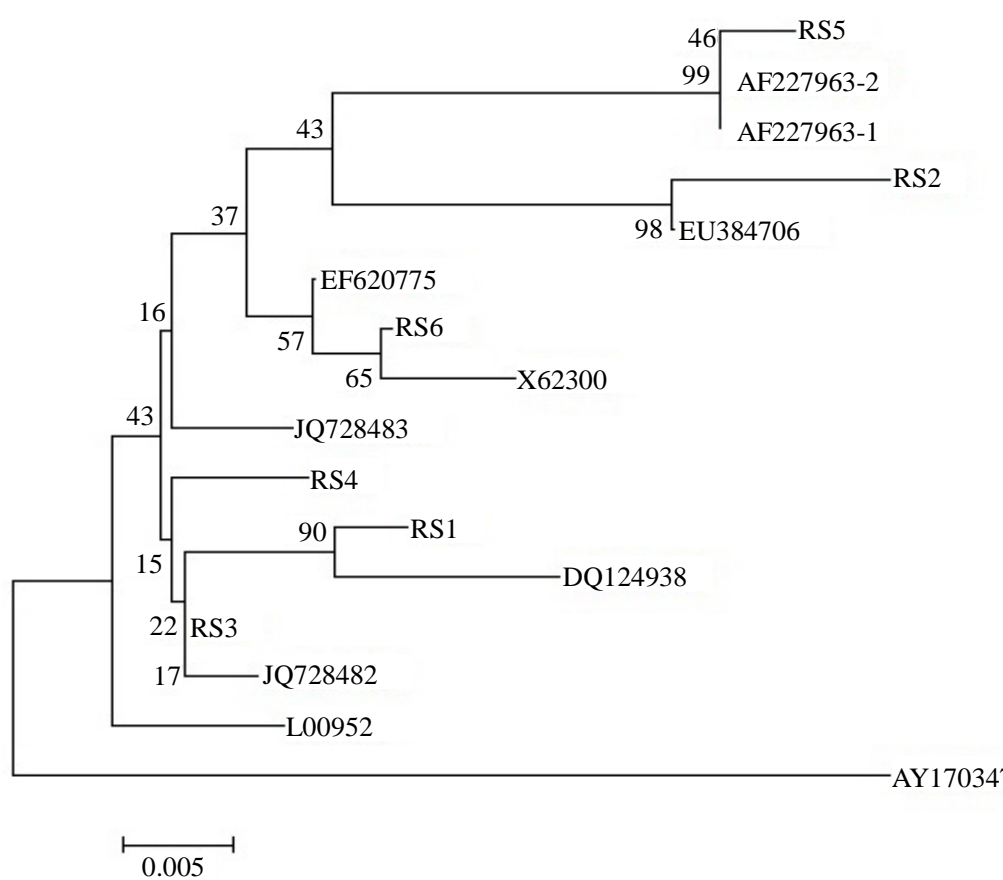

Figure 4. Phylogenetic tree analysis of RS gene in peanut by MEGA 4.0 program based on the amino acid sequences. RS1 - RS6: the deduced amino acid sequences for cloned RS genes from peanut “ZhenZhuHong” variety. AF227963, AY170347, DQ124938, EF620775, EU384706, JQ728482, JQ728483, L00952 and X62300 are the accession number of RS genes obtained from in public database. 

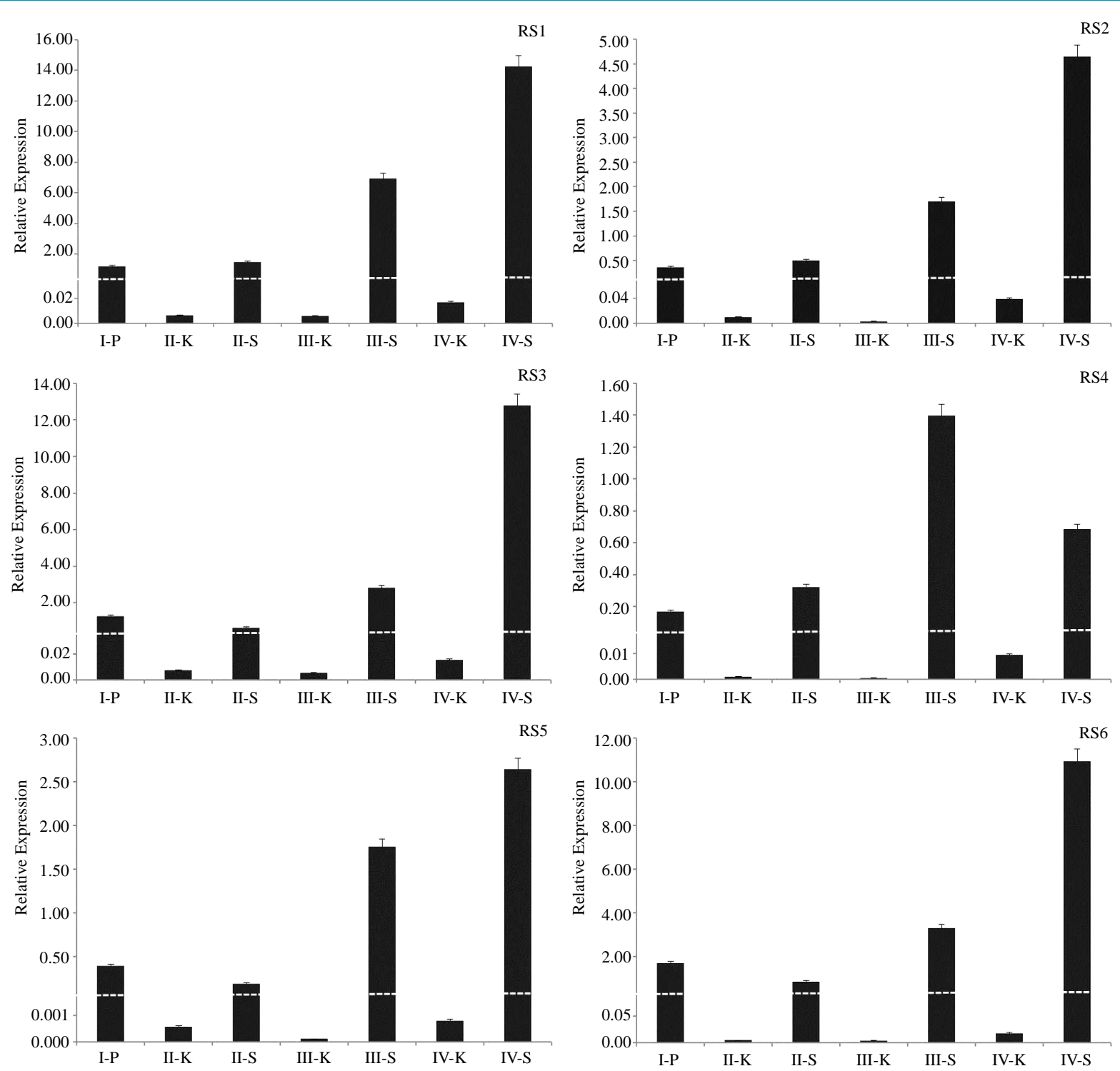

Figure 5. Expression pattern analysis of six RS genes in pods at different development stage by QRT-PCR. I: Tissue differentiation stag, II: Cotyledon elongation stage, III: Main leaf elongation stage, IV: Mature stage, K: Peanut kernel, S: Peanut shell. The values shown in this figure are the average of three independent expriment. Error bars represent the SD $(n=3)$ of relative mRNA expression levels of RS genes normalized to endogenous actin expression.

genes were introduced into onion epidermal cells by Agrobacterium tumefaciens-mediated transformation to express the fusion protein under control of the cauliflower mosaic virus (CaMV) 35S promoter. The sGFP fluorescence was imaged under a laser-scanning confocal microscope. Figure 6, $\mathrm{P}_{\text {Camv35s }}:$ RS1:mGFP and $\mathrm{P}_{\text {CaMv35s: }}: \mathrm{RS5}$ : mGFP fusion protein were found to be expressed in the nucleus and plasma membrane respectively, while the

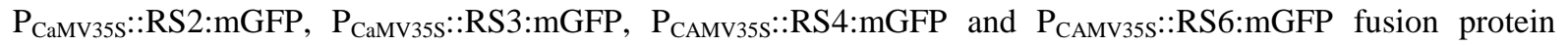
were located in both nucleus inner membrane and plasma membrane.

\section{Discussion}

Prior investigations have provided documentary evidence indicating that resveratrol has been founded in more than 70 plant species and is mainly present in dietary plants, such as peanut, grapes and purple sweet potato It has been reported that RS genes are multiple copy in many plants [35] [36]. To learn more about the resveratrol biosynthesis in peanuts, we investigated the genes encoding RS distribution in peanut. In the present study, six 

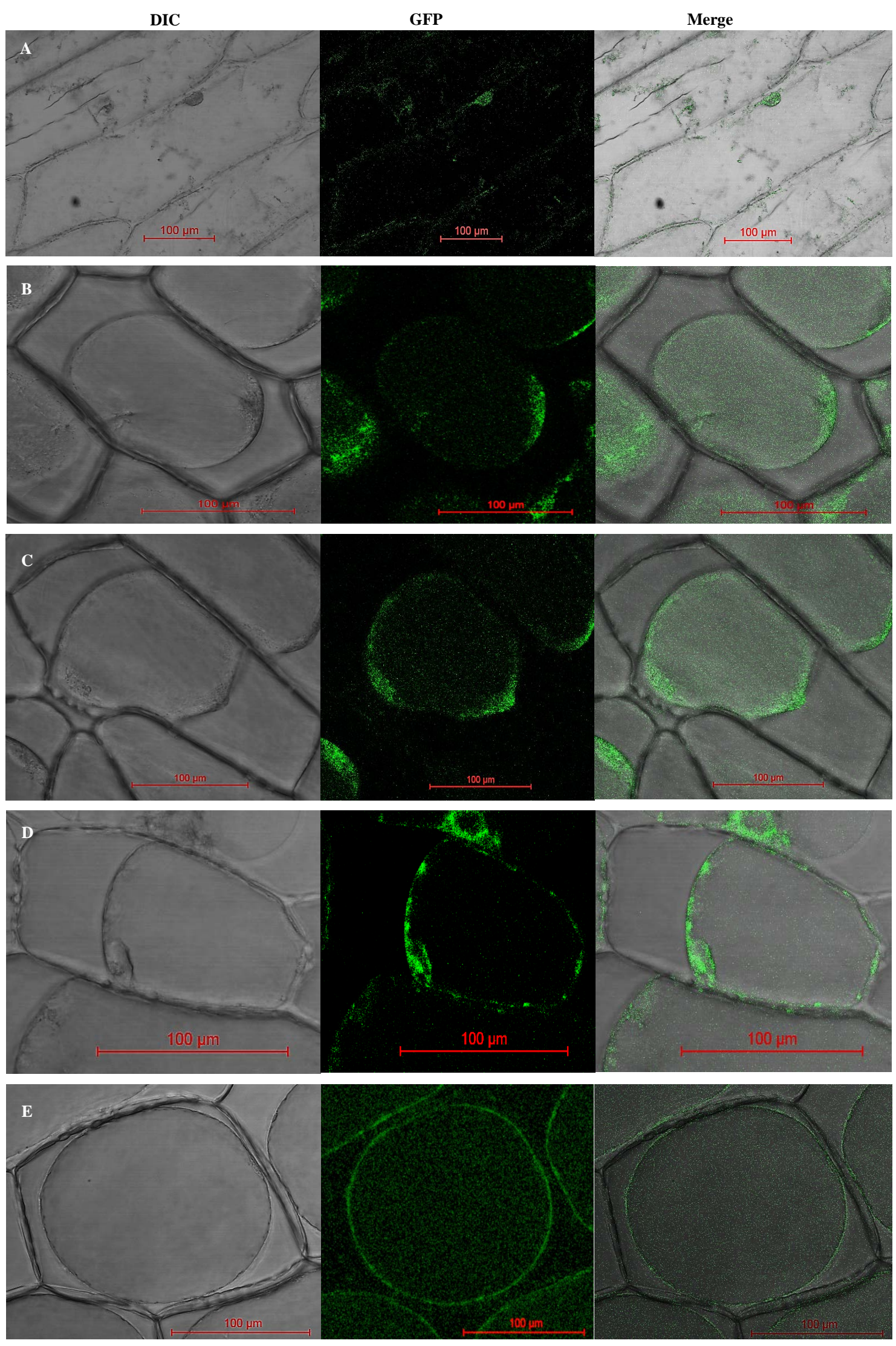

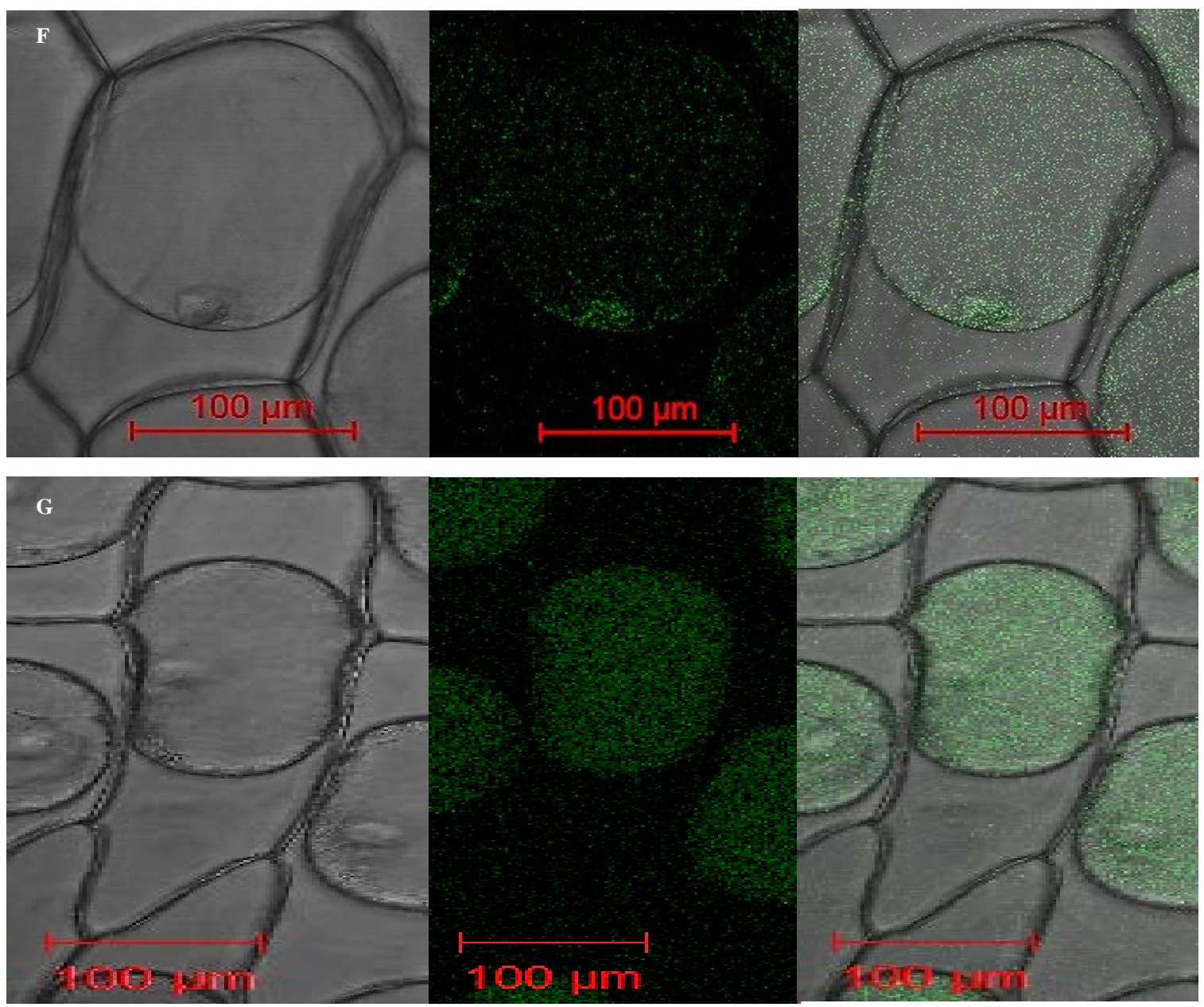

Figure 6. Subcellular localization of six RS genes. The six RS: GFP fusion protein and GFP only expressed under controlled of CaMV35S promoter in nion epidermal cells by agrobacterium tumefaciens-mediated transformation and monitored by scanning confocal microscope. A-F: RS1-RS6 fusion with GFP protein under control of CaMV35S promoter, G: pCAMBIA1302 Vector, the expression of GFP protein controlled by CaMV35S promoter.

RS genes were cloned and characterized from the peanut "Zhenzhu Hong” variety. The deduced amino acid sequence homologies among six RS genes were $95 \%$ - 99\%, while the identity with those peanut RS genes in the public database among 92\% - 98\%, only contain a few of amino acid various in some varieties. All of the amino acid sequence contained Chal_Sti_Synt_N and ACP_Syn_III_C domain. This implies that RS genes were highly evolutionarily conserved in peanuts; which is also supported by the amino acid alignment (Figure 3) and phylogenetic analysis (Figure 4). These genes most likely fulfill the same function and their transcription is activated in response to different environmental conditions and developmental stages in the peanut. The concentrations of resveratrol in the plants is comparatively low under the natural cultivation, but when plants are exposed to bacterial, fungal and other serious biotic stresses or $U V$ irradiation, wounding and other severe abiotic stresses, the phytoalexin resveratrol cannot be accumulated to a sufficient level if encoded by a single gene. Plants have overcome this shortcoming by evolving multiple copies of RS genes in order to counteract biotic and abiotic stress.

RS gene expression plays an important role in resveratrol synthesis and accumulation in plant tissues. The previous studies showed that, RS mRNA have detected in the peanut leaves, roots, pods, kernels, and kernel skins, and resveratrol relatively abundant in the peanut roots and shells but seeds when plants grown under the natural condition [37]-[40]. In the study, expression pattern analysis displayed the six RS genes were mainly expressed in the peanut shell at different developmental stages with different expression levels, but lower levels of them were evident in the peanut kernel. There is a correlation between resveratrol and RS mRNA accumulation, 
and these results indicated tissue-specific distribution of RS gene and regulation of resveratrol synthesis in peanut. Since multiple copy RS gene present and express in peanut, On the other hand, these also indicate that peanut is an important dietary and available source of resveratrol, and resveratrol also accumulated by elicitor and abiotic stresses. And it has reported that, the expression of RS gene also can be induced by $U V$ and hurt damage [20] [41] [42]. In addition, further investigation is required to determine whether all of accumulation in biotic and abiotic stress.

The particular subcellular location of RS protein was considered to be related to its physiological function in the enzymology research. The buckwheat RS protein is located in the cytosol and associates with the cytoplasmic and ER but not in nuclei plastids, mitochondria, Golgi, or tonoplasts [43]. Qiu et al. pointed out that RS protein in grape was mainly located on the cell wall [44]. Subcellular location of RS protein in this study showed that RS1 and RS5 were found to be expressed in the nucleus and plasma membrane respectively, while the RS2, RS3, RS4 and RS6 were located in both nucleus inner membrane and plasma membrane. It may indicate that RS2, RS3, RS4 and RS6 may play on same function and pattern, while RS1 and RS5 apart from them. The other explanation is that they function in different subcellular at the different development stage. The difference on the RS subcellular location in different organs indicated that different regulation mechanism might exist in different organs.

\section{Conclusion}

In summary, in this study six peanut RS genes has been isolated, characterized and analyzed the tissues expression patterns, and analyzed the localization of RS protein product. The data thus provide the molecular bases for future functional, regulatory mechanisms and enzyme kinetics studies of the peanut RS genes.

\section{Acknowledgements}

This research was funded by grants from National Natural Science Foundation of China (No. 31200155 and 31271767), Pearl River Science and Technology Nova of Guangzhou (No. 2011J2200035), Science and Technology Planning Project of Guangdong Province (No. 2011B010500019, 2012B050700007), and supported by the earmarked fund for Modern Agro-industry Technology Research System (CARS-14) and foundation of CRI/GDAAS (2012-2). The founders had no role in study design, data collection and analysis, decision to publish, or preparation of the manuscript. We declare no conflict of interests.

\section{References}

[1] Dao, T.T.H., Linthorst, H.J.M. and Verpoorte, R. (2011) Chalcone Synthase and Its Functions in Plant Resistance. Phytochemistry Reviews, 10, 397-412. http://dx.doi.org/10.1007/s11101-011-9211-7

[2] Jeandet, P., Delaunois, B., Conreux, A., et al. (2010) Biosynthesis, Metabolism, Molecular Engineering, and Biological functions of stilbene phytoalexins in plants. BioFactors, 36, 331-341. http://dx.doi.org/10.1002/biof.108

[3] Beekwilder, J., Wolswinkel, R., Jonker, H., et al. (2006) Production of Resveratrol in Recombinant Microorganisms. Applied and Environmental Microbiology, 72, 5670-5672. http://dx.doi.org/10.1128/AEM.00609-06

[4] Horinouchi, S. (2009) Combinatorial Biosynthesis of Plant Medicinal Polyketides by Microorganisms. Current Opinion in Chemical Biology, 13, 197-204. http://dx.doi.org/10.1016/j.cbpa.2009.02.004

[5] Csiszar, A., Bagi, Z., Feher, A., et al. (2011) Resveratrol Confers Endothelial Protection via Activation of the Antioxidant Transcription Factor Nrf2. The FASEB Journal, 25, 1093.13.

[6] Lee, H.S., Lee, B.W., Kim, M.R., et al. (2010) Syntheses of Resveratrol and Its Hydroxylated Derivatives as Radical Scavenger and Tyrosinase Inhibitor. Bulletin of the Korean Chemical Society, 31, 971-975.

http://dx.doi.org/10.5012/bkcs.2010.31.04.971

[7] Elmali, N., Baysal, O., Harma, A., et al. (2007) Effects of Resveratrol in Inflammatory Arthritis. Inflammation, 30, 1-6. http://dx.doi.org/10.1007/s10753-006-9012-0

[8] Athar, M., Back, J.H., Kopelovich, L., et al. (2009) Multiple Molecular Targets of Resveratrol: Anti-Carcinogenic Mechanisms. Archives of Biochemistry and Biophysics, 486, 95-102. http://dx.doi.org/10.1016/j.abb.2009.01.018

[9] Shukla, Y. and Singh, R. (2011) Resveratrol and Cellular Mechanisms of Cancer Prevention. Annals of the New York Academy of Sciences, 1215, 1-8. http://dx.doi.org/10.1111/j.1749-6632.2010.05870.x

[10] Baur, J.A., Pearson, K.J., Price, N.L., et al. (2006) Resveratrol Improves Health and Survival of Mice on a High-Calorie Diet. Nature, 444, 337-342. http://dx.doi.org/10.1038/nature05354 
[11] Brisdelli, F., D’Andrea, G. and Bozzi, A. (2009) Resveratrol: A Natural Polyphenol with Multiple Chemopreventive Properties (Review). Current Drug Metabolism, 10, 530-546. http://dx.doi.org/10.2174/138920009789375423

[12] Fulda, S. (2010) Resveratrol and Derivatives for the Prevention and Treatment of Cancer. Drug Discovery Today, 15, 757-765. http://dx.doi.org/10.1016/j.drudis.2010.07.005

[13] Hsieh, T. and Wu, J.M. (2010) Resveratrol: Biological and Pharmaceutical Properties as Anticancer Molecule. BioFactors, 36, 360-369. http://dx.doi.org/10.1002/biof.105

[14] Vang, O., Ahmad, N., Baile, C.A., Baur, J.A., Brown, K., Csiszar, A., et al. (2011) What Is New for an Old Molecule? Systematic Review and Recommendations on the Use of Resveratrol. PLOS ONE, 6, e19881. http://dx.doi.org/10.1371/journal.pone.0019881

[15] Kasiotis, K.M., Pratsinis, H., Kletsas, D. and Haroutounian, S.A. (2013) Resveratrol and Related Stilbenes: Their AntiAging and Anti-Angiogenic Properties. Food and Chemical Toxicology, 61, 112-120. http://dx.doi.org/10.1016/j.fct.2013.03.038

[16] Chong, J., Poutaraud, A. and Hugueney, P. (2009) Metabolism and Roles of Stilbenes in Plants. Plant Science, 177, 143-155. http://dx.doi.org/10.1016/j.plantsci.2009.05.012

[17] Guerrero, R.F., Puertas, B., Fernández, M.I., Palma, M. and Cantos-Villar, E. (2010) Induction of Stilbenes in Grapes by UV-C: Comparison of Different Subspecies of Vitis. Innovative Food Science \& Emerging Technologies, 11, 231238. http://dx.doi.org/10.1016/j.ifset.2009.10.005

[18] Tang, K., Zhan, J.C., Yang, H.R. and Huang, W.D. (2010) Changes of Resveratrol and Antioxidant Enzymes during UV-Induced Plant Defense Response in Peanut Seedlings. Journal of Plant Physiology, 167, 95-102. http://dx.doi.org/10.1016/j.jplph.2009.07.011

[19] Hammerbacher, A., Ralph, S.G., Bohlmann, J., Fenning, T.M., Gershenzon, J. and Schmidt, A. (2011) Biosynthesis of the Major Tetrahydroxystilbenes in Spruce, Astringin and Isorhapontin, Proceeds via Resveratrol and Is Enhanced by Fungal Infection. Plant Physiology, 157, 876-890. http://dx.doi.org/10.1104/pp.111.181420

[20] Dubrovina, A.S. and Kiselev, K.V. (2012) Effect of Long-Term Cultivation on Resveratrol Accumulation in a High-Producing Cell Culture of Vitis amurensis. Acta Physiologiae Plantarum, 34, 1101-1106. http://dx.doi.org/10.1007/s11738-011-0907-5

[21] Lu, D., Zhao, W., Zhu, K. and Zhao, S. (2012) Relevant Enzymes, Genes and Regulation Mechanisms in Biosynthesis Pathway of Stilbenes. Open Journal of Medicinal Chemistry, 2, 15-23. http://dx.doi.org/10.4236/ojmc.2012.22003

[22] Schröder, G., Brown, J.W. and Schröder, J. (1988) Molecular Analysis of Resveratrol Synthase. European Journal of Biochemistry, 172, 161-169.

[23] Lanz, T., Schroder, G. and Schroder, J. (1990) Differential Regulation of Genes for Resveratrol Synthase in Cell Cultures of Arachis hypogaea L. Planta, 181, 169-175. http://dx.doi.org/10.1007/BF02411534

[24] Wang, B.Y., Pan, H.F., Ye, B.Y., et al. (2005) Cloning and Sequence Analysis of Resveratrol Synthase DNA from Peanut (Arachis hypogaea L.). Journal of Fujian Normal University (Natural Science), 21, 56-60.

[25] Huang, X.Q., Guo, L.Q., Li, X.M., Lin, J.F., Yuan, Z.H. and Tan, M.C. (2012) Cloning and Sequence Analysis of Resveratrol Synthase Gene from Peanut(Arachis hypogaea L.). Biotechnology Bulletin, 3, 69-74.

[26] Delaunois, B., Cordelier, S., Conreux, A., Clément, C. and Jeandet, P. (2009) Molecular Engineering of Resveratrol in Plants. Plant Biotechnology Journal, 7, 2-12. http://dx.doi.org/10.1111/j.1467-7652.2008.00377.x

[27] Trantas, E., Panopoulos, N. and Ververidis, F. (2009) Metabolic Engineering of the Complete Pathway Leading to Heterologous Biosynthesis of Various Flavonoids and Stilbenoids in Saccharomyces cerevisiae. Metabolic Engineering, 11, 355-366. http://dx.doi.org/10.1016/j.ymben.2009.07.004

[28] Jeandet, P., Delaunois, B., Aziz, A., Donnez, D., Vasserot, Y., Cordelier, S. and Courot, E. (2012) Metabolic Engineering of Yeast and Plants for the Production of the Biologically Active Hydroxystilbene, Resveratrol. Journal of Biomedicine and Biotechnology, 2012, 1-14. http://dx.doi.org/10.1155/2012/579089

[29] Hain, R., Bieseler, B., Kindl, H., Schröder, G. and Stöcker, R. (1990) Expression of a Stilbene Synthase Gene in Nicotiana tabacum Results in Synthesis of the Phytoalexin Resveratrol. Plant Molecular Biology, 15, 325-335. http://dx.doi.org/10.1007/BF00036918

[30] Yu, C.K.Y., Springob, K., Schmidt, J., Nicholson, R.L., Chu, I.K., Yip, W.K. and Lo, C. (2005) A Stilbene Synthase Gene (SbSTS1) Is Involved in Host and Nonhost Defense Responses in Sorghum. Plant Physiology, 138, 393-401. http://dx.doi.org/10.1104/pp.105.059337

[31] Christine, K.Y., Lam, C.N.W., Springob, K., Schmidt, J., Chu, I.K. and Lo, C. (2006) Constitutive Accumulation of cis-Piceid in Transgenic Arabidopsis Overexpressing a Sorghum Stilbene Synthase Gene. Plant and Cell Physiology, 47, 1017-1021. http://dx.doi.org/10.1093/pcp/pcj061

[32] Halls, C. and Yu, O. (2008) Potential for Metabolic Engineering of Resveratrol Biosynthesis. Trends in Biotechnology, 
26, 77-81. http://dx.doi.org/10.1016/j.tibtech.2007.11.002

[33] Pan, L.P., Yu, S.L., Chen, C.J., Li, H., Wu, Y.L. and Li, H.H. (2012) Cloning a Peanut Resveratrol Synthase Gene and Its Expression in Purple Sweet Potato. Plant Cell Reports, 31, 121-131. http://dx.doi.org/10.1007/s00299-011-1145-4

[34] He, X., Wang, L., Szklarz, G., Bi, Y.Y. and Ma, Q. (2012) Resveratrol Inhibits Paraquat-Induced Oxidative Stress and Fibrogenic Response by Activating the Nuclear Factor Erythroid 2-Related Factor 2 Pathway. Journal of Pharmacology and Experimental Therapeutics, 342, 81-90. http://dx.doi.org/10.1124/jpet.112.194142

[35] Preisig-Müller, R., Schwekendiek, A., Brehm, I., Reif, H.J. and Kindl, H. (1999) Characterization of a Pine Multigene Family Containing Elicitor-Responsive Stilbene Synthase Genes. Plant Molecular Biology, 39, 221-229. http://dx.doi.org/10.1023/A:1006163030646

[36] Zhou, Y., Yang, Y., Huang, J., et al. (2008) Cloning and Analysis of Resveratrol Synthase Gene Family. Chinese Journal of Oil Crop Sciences, 2, 8.

[37] Chen, R.S., Wu, P.L. and Chiou, R.Y.Y. (2002) Peanut Roots as a Source of Resveratrol. Journal of Agricultural and Food Chemistry, 50, 1665-1667. http://dx.doi.org/10.1021/jf011134e

[38] Chung, I.M., Park, M.R., Rehman, S. and Yun, S.J. (2001) Tissue Specific and Inducible Expression of Resveratrol Synthase Gene in Peanut Plants. Molecules and Cells, 12, 353-359.

[39] Chung, I.M., Park, M.R., Chun, J.C. and Yun, S.J. (2003) Resveratrol Accumulation and Resveratrol Synthase Gene Expression in Response to Abiotic Stresses and Hormones in Peanut Plants. Plant Science, 164, 103-109. http://dx.doi.org/10.1016/S0168-9452(02)00341-2

[40] Galgut, J.M. and Ali, S.A. (2011) Effect and Mechanism of Action of Resveratrol: A Novel Melanolytic Compound from the Peanut Skin of Arachis hypogaea. Journal of Receptors and Signal Transduction, 31, 374-380. http://dx.doi.org/10.3109/10799893.2011.607170

[41] Adrian, M., Jeandet, P., Bessis, R. and Joubert, J.M. (1996) Induction of Phytoalexin (Resveratrol) Synthesis in Grapevine Leaves Treated with Aluminum Chloride $\left(\mathrm{AlCl}_{3}\right)$. Journal of Agricultural and Food Chemistry, 44, 1979-1981. http://dx.doi.org/10.1021/jf950807o

[42] Rudolf, J.R. and Resurreccion, A.V.A. (2005) Elicitation of Resveratrol in Peanut Kernels by Application of Abiotic Stresses. Journal of Agricultural and Food Chemistry, 53, 10186-10192. http://dx.doi.org/10.1021/jf0506737

[43] Hrazdina, G. and Jensen, R.A. (1992) Spatial Organization of Enzymes in Plant Metabolic Pathways. Annual Review of Plant Physiology and Plant Molecular Biology, 43, 241-267. http://dx.doi.org/10.1146/annurev.pp.43.060192.001325

[44] Pan, Q.H., Wang, L. and Li, J.M. (2009) Amounts and Subcellular Localization of Stilbene Synthase in Response of Grape Berries to UV Irradiation. Plant Science, 176, 360-366. http://dx.doi.org/10.1016/j.plantsci.2008.12.004 
Scientific Research Publishing (SCIRP) is one of the largest Open Access journal publishers. It is currently publishing more than 200 open access, online, peer-reviewed journals covering a wide range of academic disciplines. SCIRP serves the worldwide academic communities and contributes to the progress and application of science with its publication.

Other selected journals from SCIRP are listed as below. Submit your manuscript to us via either submit@scirp.org or Online Submission Portal.
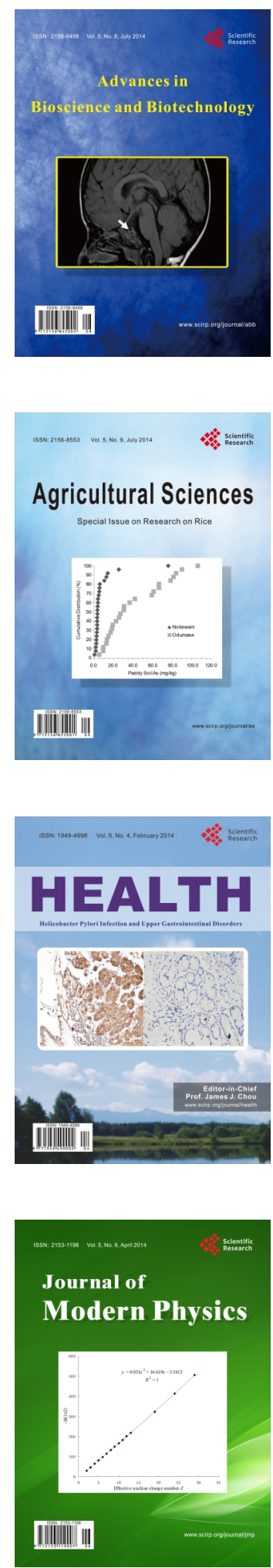
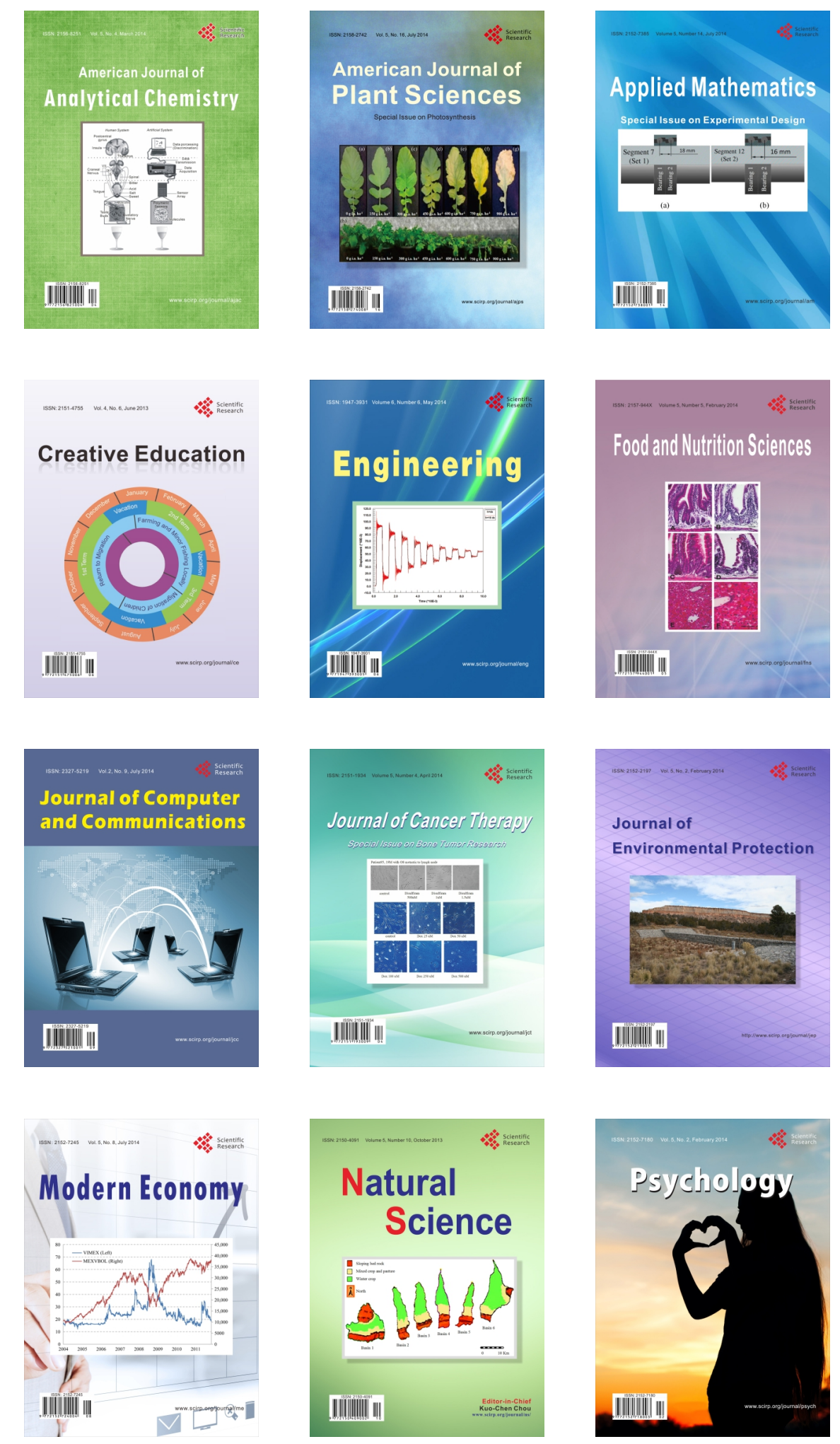